\title{
AUTOMATIC DETECTION OF FOREST-ROAD DISTANCES TO IMPROVE CLEARING OPERATIONS IN ROAD MANAGEMENT
}

\author{
A. Novo ${ }^{1 *}$, H. González-Jorge ${ }^{2}$, J. Martínez-Sánchez ${ }^{1}$, L.M. González-de Santos ${ }^{1}$, H. Lorenzo ${ }^{3}$ \\ ${ }^{1}$ Geotech Group, Department of Natural Resources and Environmental Engineering, School of Mining Engineering, University of \\ Vigo, 36310, Vigo, Spain - (annovo, joaquin.martinez,luismgonzalez)@uvigo.es \\ ${ }^{2}$ Geotech Group, Department of Natural Resources and Environmental Engineering, School of Aerospace Engineering, University of \\ Vigo, 32004, Ourense, Spain - higiniog@uvigo.es \\ ${ }^{3}$ Geotech Group, Department of Natural Resources and Environmental Engineering, School of Forestry Engineering, University of \\ Vigo, 36005, Pontevedra, Spain - hlorenzo@uvigo.es
}

\section{Commission II, WG II/10}

KEY WORDS: Mobile LiDAR, Road Safety Distance, Forestry Management, Forest Fire, Point Cloud Processing

\begin{abstract}
:
There is a complex relation between roads and fires. Several major wildfires were ignited near to roads (Morrison 2007) and how they progressed is an important role to understand the importance to forest management in this environment. Nowadays, a sustainable forest management is necessary both for environment and politics. One of the reasons of road management is that these infrastructures provide an effective firewall in case of forest fires and an escape route for the population. Forest management optimization in road surroundings would improve wildfires prevention and mitigate their effects. One of the main indicators of road safety is the distance between road and vegetation.

The aim of this work is to develop a methodology to determine what areas do not obey current laws about safety distances between forest and roads. The acquisition of LiDAR data is done by Lynx Mobile Mapper System from University of Vigo. The methodology is automated using LiDAR data processing. The developed algorithms are based in height and length segmentation of the road. The objective is classifying vegetation groups by height and calculate the distance to the edges of road. The vegetation is divided in groups of height of 5,10,15 and $30 \mathrm{~m}$. The minimum distance calculation is $2 \mathrm{~m}$, for the vegetation of $5 \mathrm{~m}$ height and a maximum of $60 \mathrm{~m}$ for vegetation $30 \mathrm{~m}$ height. The height of vegetation has a directly relation with the distance separation with the road
\end{abstract}

\section{INTRODUCTION}

\subsection{General Instructions}

Nowadays, the management of forest stands is a necessity for scientific, environmental and political studies. Prevention is one of the fundamental bases in the fight against forest fires (Xunta de Galicia, 2012). There is a complex relation between road and fires. The areas close to roads have many time more wildfires occurrences that areas distant of them (Morrison, 2007). Sierra Nevada Ecosystem Project (McKelvey et al., 1996) indicated the location of multiple-burn sites were associated with busy roads. An efficient forest management in roads surroundings would improve wildfires prevention and mitigate their effects. The law about prevention and defence against forest fires in Galicia (Xunta de Galicia, 2007) establishes a distance between four and ten meters to the road, depending the type of tree species.

In recent years, LiDAR technology has undergone great advances and show applicability to forest management. It has become a source of high precision geometric data with reduced human resources, which in many cases would be impossible to obtain by other techniques.

Studies of Mobile Lase Scanning (MLS) were conducted in forest environment before 2013 (Holopainen et al., 2013). MLS data sets are well suited to detect single trees and to model 3D trees in a highly automated manner. They preserve the outer shape of high vegetation objects, which represents the characteristics canopy shape and tree structure (Rutzinger et al., 2010; Saarinen et al., 2013). An automatic classification of trees from laser scanning points clouds by labelling each point to indicate whether it belongs to the tree class. The possible usage of the algorithm is an important step for tree growth observation, tree counting and similar applications, but weakness, false detection of light poles, traffic sings and other objects close to trees cannot be prevent (Sirmacek and Lindenbergh, 2015).

The installation of laser scanners on moving platforms has been studied as a convenient measurement method for forest mapping during several years. There are studies relating to the detection, classification and analysis of characteristics of single trees. However, there are not many studies relating to forest management as a whole.

The importance of prevented possible irregularities in the forest management that could influence the propagation of a forest fire is very important. In this way to determine the distance between vegetation and roads could be an important step to identify risks zones in terms of forest fires. On the other hand, the detection of vegetation that not comply with the distances stablished in a current law could be an interest instrument for the municipalities and other authorities that need to build spatial datasets from the public space they manage.

The aim of this work is to analyse the potential application of MLS to mapping nearest vegetation to roads and verify the safety distances between forest and roads by developing a 
methodology to automatize the data processing. Firstly, the point cloud is segmented in slices of $1 \mathrm{~m}$ and then each slice is analysed by height segmentation. The heights used in this study was $1.30,5,15$ and $30 \mathrm{~m}$. Finally, a buffer for each height section are mapped. In particular, the main contributions of this study are summarized as:

- Development an algorithm to automatically redensified the points of axis and edges of the study road.

- $\quad$ Design of a methodology to group tree points by height.

Determinate the method to calculate de distance between forest and road.

Locate the risk areas of road in case of fire forest not complying with de current law.

\section{MATERIAL AND METHODS}

\subsection{Area of study}

The area of study is in the road DP-36006 located in the municipality of Ferrol, northwest Spain (Figure 1). The section of road is located between the beaches of Vilar and Esmelle giving access to them. It is a tertiary road, with double circulation direction and a maximum speed of $50 \mathrm{~km} / \mathrm{h}$. Ferrol belongs to the Forest District I (Xunta de Galicia, 2018) and should pay great attention to the prevention of forest fires. It is catalogued as a high risk area and it is also classified with a very high potential risk index (Xunta de Galicia, 2015).

There are areas of high potential risk of forest fire (ZAR) where the application of defence measures is recognised as a priority due to the risk of fires, its virulence or the importance of threatened values. In addition, the study area belongs to Natura 2000 Network and it is catalogued as a Place of Community Interest (Xunta de Galicia, 2014).

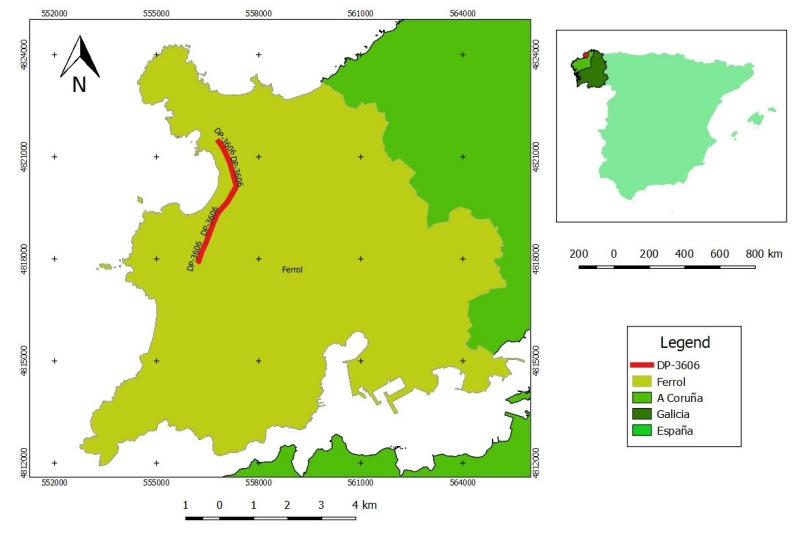

Figure 1. Location of DP-36006 road.

\subsection{Mobile LiDAR system}

The experimental data for this work were collected using the Lynx Mobile Mapper (Figure 2) by OPTECH (Optech, 2011). This system was previously used in many road management studies (González-Jorge et al., 2016; Puente et al., 2014; Riveiro et al., 2015; Soilán et al., 2016).

The Lynx Mobile Mapper generates rich survey-grade LiDAR and image data. The system is composed by two LiDAR sensor heads with 500.000 measurements per second and a field of view (FOV) of $360^{\circ}$. The angle between their rotational axe is $90^{\circ}$ and they have an angle of $45^{\circ}$ with respect to the trajectory of the vehicle. The navigation system integrates an Inertial Measurement Unit (IMU) with two GNSS antenna heading measurement system (GAMS). Furthermore, imagery data is registered by four 5-MPix JAI cameras that are synchronized by the Lynx Survey software.

The positioning system was design by APPLANIX (POS LV 520) and the GNSS receivers belong the TRIMBLE. The control software of the system enables to select the camera image frame size for highly efficient image capture (Puente ${ }^{\mathrm{a}}$ et al., 2011).

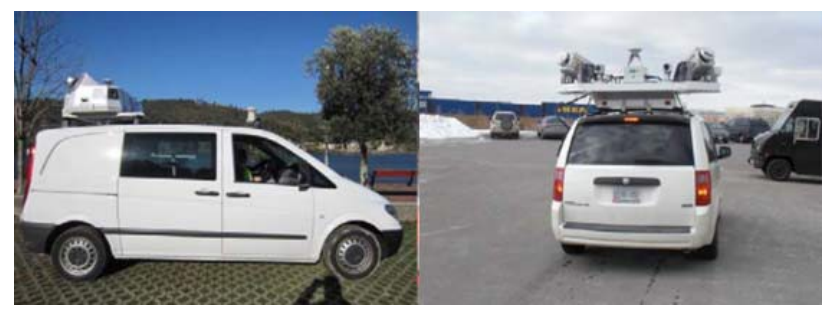

Figure 2. Mobile LiDAR System used for the survey.

Figure 3 shows the point cloud data from the area of study obtained using the Lynx Mobile Mapper. The length of road is approximate $1 \mathrm{~km}$ and the point cloud size is 10.833 .00 points. The colour bar shows different coloration by points height into the point cloud, since 0 to $57 \mathrm{~m}$.

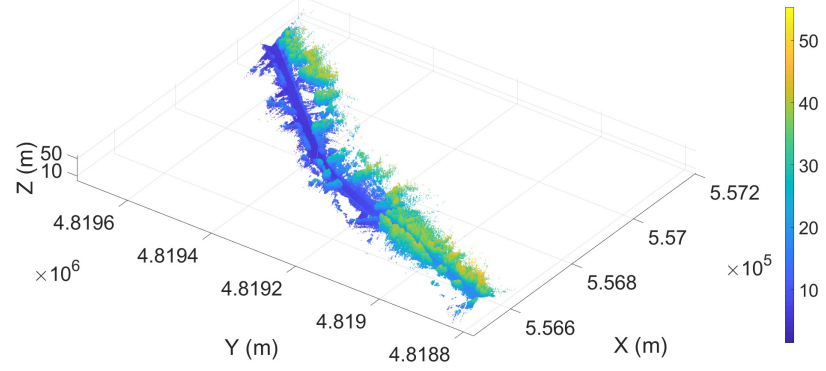

Figure 3. Point Cloud of road DP-36006 used in this study.

\subsection{Data Processing}

Algorithms and data processing is described in Figure 4. MATLAB software (MATLAB, 2019) is used for data processing. The computer on which the data processing was carried out is a MSI GP72 LEOPARD PRO, with the following technical characteristics:

- Processor: Inter(R) Core (TM) i7-7700HQ CPU @ $2.80 \mathrm{GHz}$.

- Installed RAM: 16.0 GB.

- System type: 64-bit operating system, x64-based processor. 


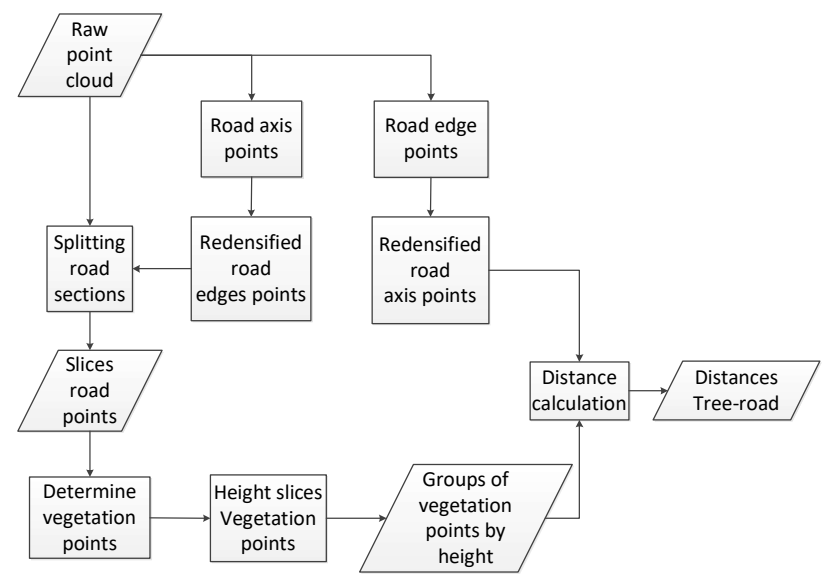

Figure 4. Workflow of the methodology to calculate distances between vegetation and road.

Data processing begins limiting the axis of the road (Figure 5). The axis of road is obtained from Cloud Compare software by point picking. This is the only manual part of the data processing. No effort has been made to automate this part, since the geometry of the road edges is usually known from road project designs or geometric as-built road inventories.

In a following step, an algorithm is implemented in MATLAB to increase the density of points from the edge of the road. This algorithm is based on a linear interpolation (Sanmiquel Pera, 2003).

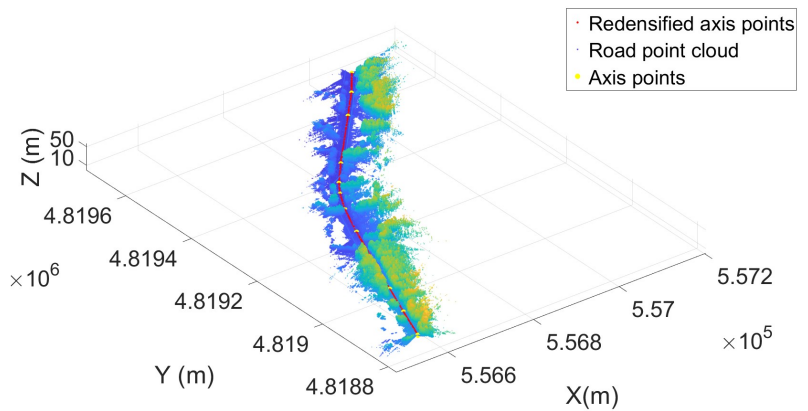

Figure 5. Redensified axis process (red points).

Once the density of axis points was increased, road point cloud is divided into $1 \mathrm{~m}$ slices according to direction of the vehicle driving (Figure 6). Thus, the data are easier to handle and slope effect of the road cloud be avoided.

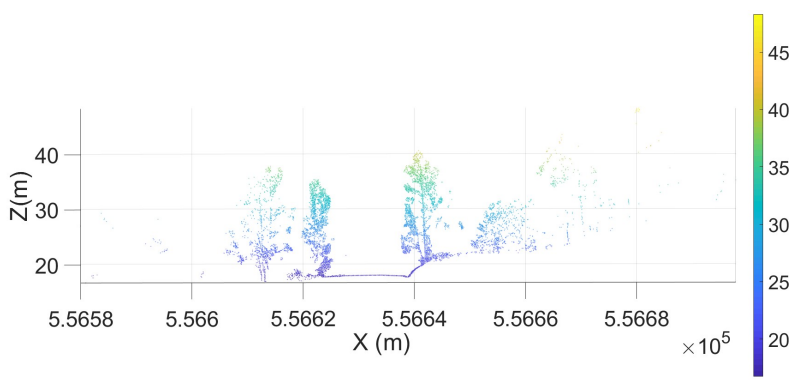

Figure 6. Slice example of 1 meter of length of road. Tree vegetation can be easily identified.
Next step is focused to identification of vegetation points into a point cloud for this purpose a height restriction is used. Axis points were used to determine which points had a upper bound in each section. In this way vegetation points were grouped removing road points (Figure 7)

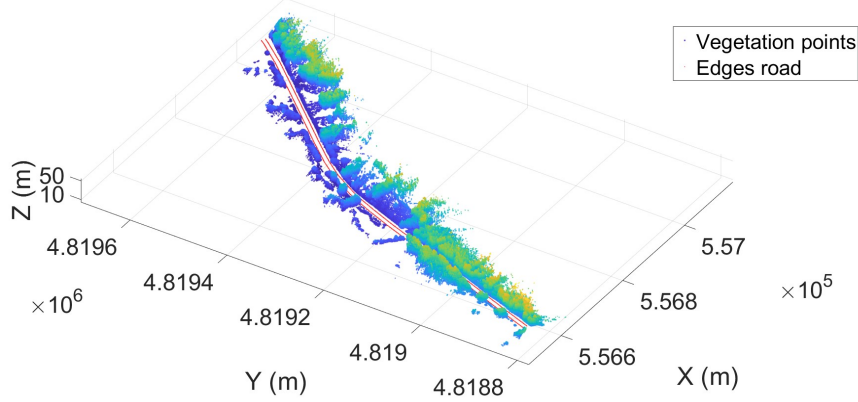

Figure 7. Vegetation points of road, limits of road are showed in red colour.

In the previous step to distance calculation, the vegetation points were splitting by height with the purpose to characterize the risk of having a canopy fire forest. For this purpose, the process was the same than to the division into length slices. The height used in this study are vegetation greater than $5 \mathrm{~m}, 10 \mathrm{~m}$, $15 \mathrm{~m}$ and $30 \mathrm{~m}$ (Figure 8-11).

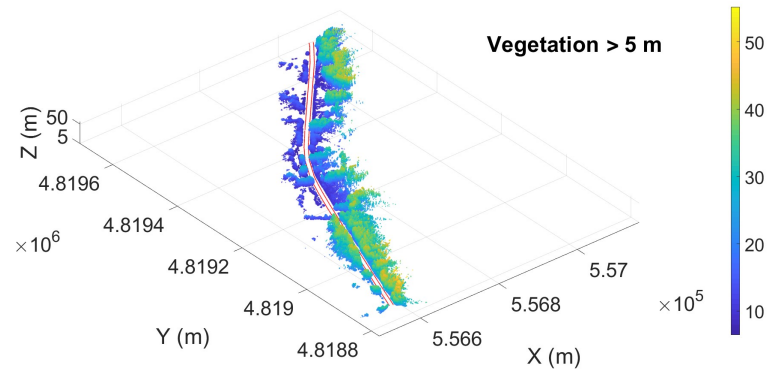

Figure 8. Vegetation points with greater height than $5 \mathrm{~m}$.

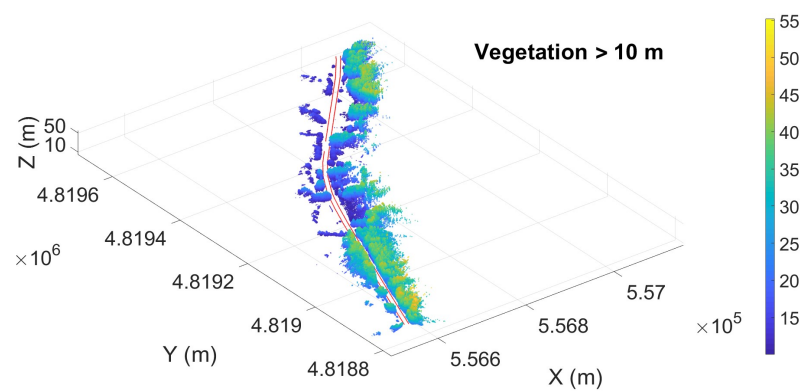

Figure 9. Vegetation points with greater height than $10 \mathrm{~m}$ 


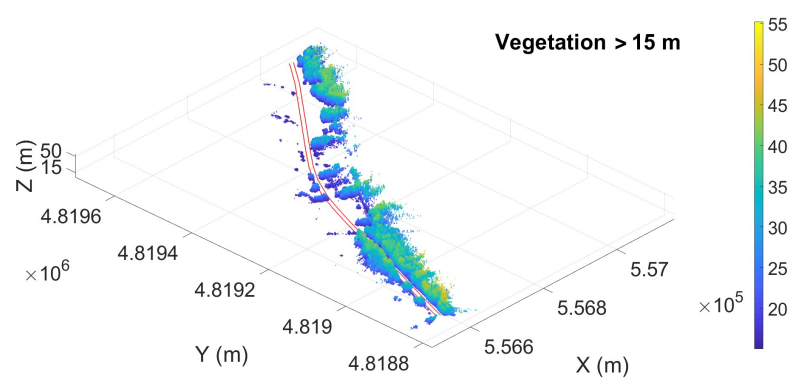

Figure 10. Vegetation points with greater height than $15 \mathrm{~m}$.

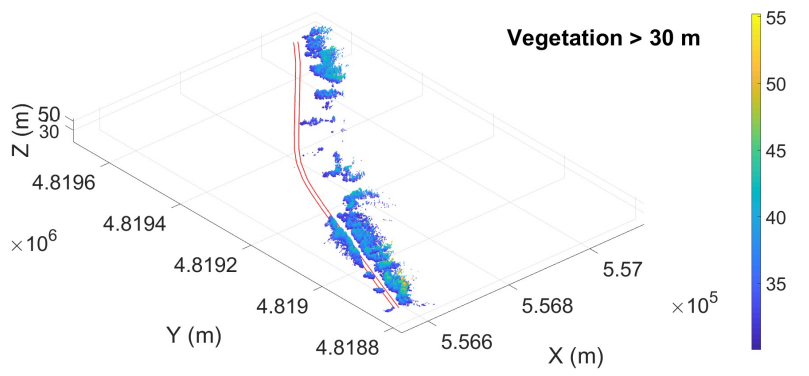

Figure 11. Vegetation points with greater height than $30 \mathrm{~m}$.

After to grouped vegetation by heights the distance between vegetation and road was calculated. In this process is used both edges of road that like axis road were marker previously from Cloud Compare software by point picking. Likewise, to increase the density of points was obtained by linear interpolation. Once, the re-densified edges points are obtained the distance is calculated to vegetation points based on to find the nearest neighbour for each edge point uses the method of Euclidean distance (Friedman et al., 1976).

\section{RESULTS AND DISCUSSION}

Figures 12-15 and table 1 show the results for different vegetation groups studied divided by height $5 \mathrm{~m}, 10 \mathrm{~m}, 15 \mathrm{~m}$ and $30 \mathrm{~m}$.

The vegetation detected in the study area is very near to edges of road. With the consideration of high slices, the presence of vegetation lower than $5 \mathrm{~m}$ is only localized two meters of distance to the edges of road. On the other hand, there are vegetation to $15 \mathrm{~m}$ of distance. But the mean distance of this group of vegetation is $10 \mathrm{~m}$.

In the group of vegetation higher of $30 \mathrm{~m}$ the minimum distance with the road is $12 \mathrm{~m}$ and the maximum distance is $60 \mathrm{~m}$.

We can observe the higher trees are more distant to the road but also there are trees lower than $15 \mathrm{~m}$ and then $30 \mathrm{~m}$ in the first part of road $(29 \mathrm{~N} 556600 \mathrm{E}, 4818800 \mathrm{~N})$.

Also, it is possible to observe than in some cases the canopy is over the road. This is more danger because would help in the spread of the forest fire.

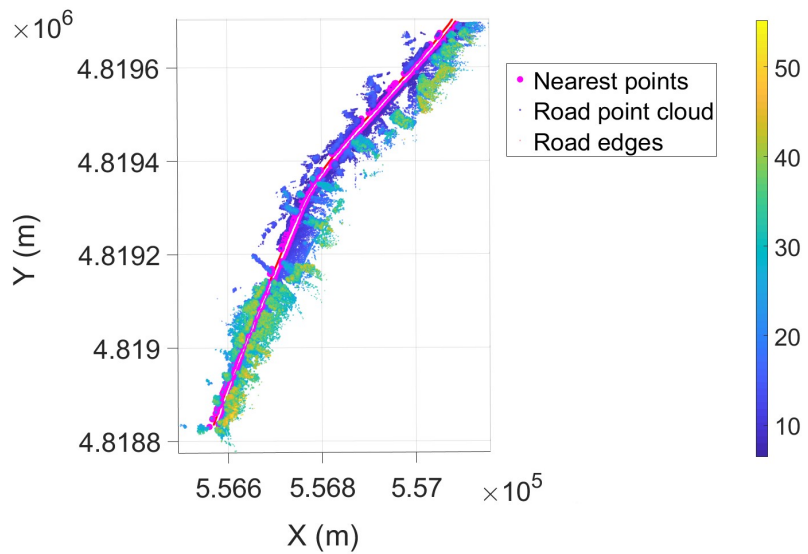

Figure 12. Vegetation detected with more than $5 \mathrm{~m}$ of height.

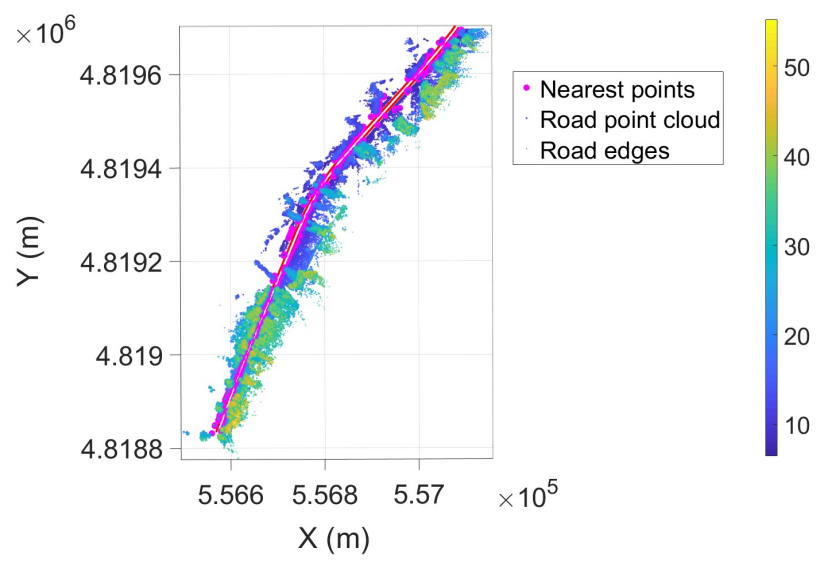

Figure 13. Vegetation detected with more than $10 \mathrm{~m}$ of height.

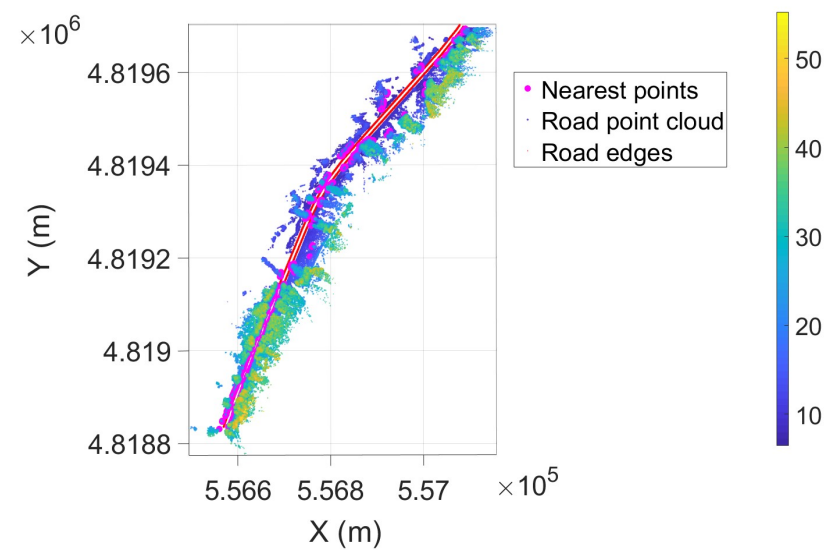

Figure 14. Vegetation detected with more than $15 \mathrm{~m}$ of height. 


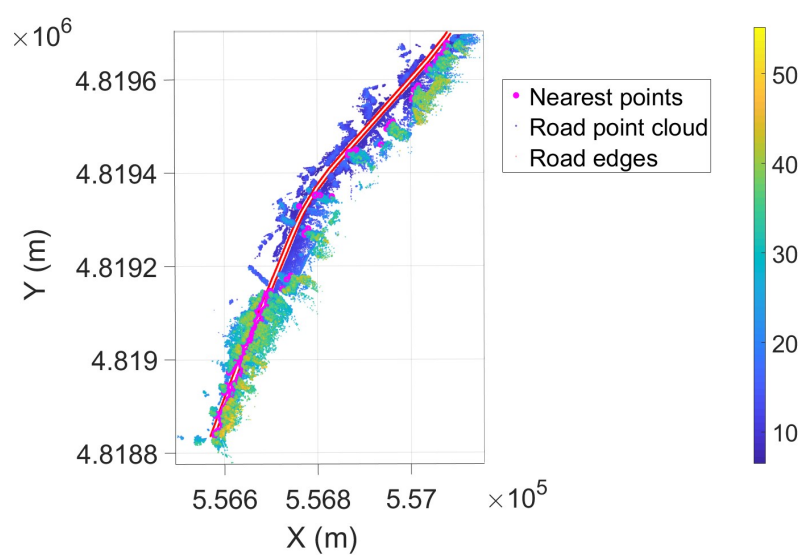

Figure 15. Vegetation detected with more than $30 \mathrm{~m}$ of height.

\begin{tabular}{c|cccc}
\multicolumn{5}{c}{ VEGETATION GROUP } \\
$\begin{array}{c}\text { Minimum } \\
\text { distance } \\
\begin{array}{c}(\boldsymbol{m}) \\
\text { Maximum }\end{array}\end{array}$ & 2,21 & 2,15 & 2,15 & 12,10 \\
$\begin{array}{c}\text { distance(m) } \\
\text { Mean } \\
\text { distance }\end{array}$ & 15,85 & 24,93 & 42,22 & 60,95 \\
$(\boldsymbol{m})$ & 9,77 & 14,18 & 26,23 & 58,50 \\
& & & &
\end{tabular}

Table 1. Distances obtained for each vegetation group studied.

\section{CONCLUSIONS}

In the road of study DP-3606 the vegetation is represented along the road. The major wooded areas are in the first part of road, but also in the final part of the road there are presence of highest trees.

It is possible to affirm that the methodology is automated, with the exception of first part in which the axis and edges of road is picked manually, because it is known by geometric of the road. This automated methodology could provide a vegetation state on roads, which is difficult to measure by human methods.

About the computational time is typically not higher than a minute and a half for the road section under study.

The use of MLS is a valid source for measurements of distance between vegetation and roads.

The current law on forest fires in Galicia stablishes that there must be a minimum distance between vegetation and the road of $4 \mathrm{~m}$ for leafy trees and $10 \mathrm{~m}$ for conifers trees. After considering the results of study, the vegetation in the environment of the road DP-3606 not comply with the current law, as it is a minimum distance of $2 \mathrm{~m}$.

The results of this study have special interest for forest management, in particular to know the state of vegetation distances safety to roads being able to potential a forest fire.

\section{ACKNOWLEDGEMENTS}

This project has received funding from the European Union's Horizon 2020 research and innovation programme under grant agreement No 769255. This document reflects only the views of the author(s). Neither the Innovation and Networks Executive Agency (INEA) nor the European Commission is in any way responsible for any use that may be made of the information it contains.

Authors would like to thank to the Universidade de Vigo for the financial support (00VI 131H 641.02). The statements made herein are solely the responsibility of the authors.

\section{REFERENCES}

Friedman, J.H., Bentley, J.L., Finkel, R.A., 1976. An algorithm for finding best matches in logarithmic time. ACM Trans. Math. Softw. 3, 209-226.

González-Jorge, H., Díaz-Vilariño, L., Lorenzo, H., Arias, P., 2016. Evaluation of driver visibility from mobile lidar data and weather conditions. Int. Arch. Photogramm. Remote Sens. Spat. Inf. Sci. 41

Holopainen, M., Kankare, V., Vastaranta, M., Liang, X., Lin, Y., Vaaja, M., Yu, X., Hyyppä, J., Hyyppä, H., Kaartinen, H., 2013. Tree mapping using airborne, terrestrial and mobile laser scanning-A case study in a heterogeneous urban forest. Urban For. urban Green. 12, 546-553.

MATLAB, 2019. Matlab Software [WWW Document]. URL https://es.mathworks.com/products/matlab.html (accessed 3.29.19).

McKelvey, K.S., Skinner, C.N., Chang, C., Erman, D.C., Husari, S.J., Parsons, D.J., van Wagtendonk, J.W., Weatherspoon, C.P., 1996. An overview of fire in the Sierra Nevada, in: Pages 1033-1040 in: Sierra Nevada Ecosystem Project, Final Report to Congress, Vol. II, Assessments and Scientific Basis for Management Options. Davis, CA: University of California, Centers for Water and Wildland Resources. Report No. 37.

Morrison, P.H., 2007. Roads and Wildfires. Pacific Biodivers. Institute, Winthrop, Washington. $40 \mathrm{p}$.

Optech, 2011. Lynx Mobile Mapper Survey Operation Manual.

Puente, I., González-Jorge, H., Martínez-Sánchez, J., Arias, P., 2014. Automatic detection of road tunnel luminaires using a mobile LiDAR system. Measurement 47, 569-575.

Puentea, I., González-Jorgea, H., Ariasa, P., Armestoa, J., 2011. Land-based mobile laser scanning systems: a review.

Riveiro, B., González-Jorge, H., Martínez-Sánchez, J., DíazVilariño, L., Arias, P., 2015. Automatic detection of zebra crossings from mobile LiDAR data. Opt. Laser Technol. 70, 63-70.

Rutzinger, M., Pratihast, A.K., Oude Elberink, S., Vosselman, G., 2010. Detection and modelling of 3D trees from mobile laser scanning data. Int. Arch. Photogramm. Remote Sens. Spat. Inf. Sci 38, 520-525.

Saarinen, N., Vastaranta, M., Vaaja, M., Lotsari, E., Jaakkola, A., Kukko, A., Kaartinen, H., Holopainen, M., Hyyppä, H., Alho, P., 2013. Area-based approach for mapping and monitoring riverine vegetation using mobile laser scanning. Remote Sens. 5, 5285-5303. https://doi.org/10.3390/rs5105285 
Sanmiquel Pera, L., 2003. Métodos planimétricos: radiación, tinerario, intersección.

Sirmacek, B., Lindenbergh, R., 2015. AUTOMATIC CLASSIFICATION OF TREES FROM LASER SCANNING POINT CLOUDS. ISPRS Ann. Photogramm. Remote Sens. Spat. Inf. Sci. 2.

Soilán, M., Riveiro, B., Martínez-Sánchez, J., Arias, P., 2016. Automatic road sign inventory using mobile mapping systems, in: The International Archives of the Photogrammetry, Remote Sensing and Spatial Information Sciences, 2016 XXIII ISPRS Congress.

Xunta de Galicia, 2018. Distritos forestales [WWW Document]. Distritos For. URL http://mediorural.xunta.gal/es/areas/forestal/ordenacion/distritos /

Xunta de Galicia, 2015. PEIFOGA [WWW Document]. Plan Espec. Protección Civ. ante Emerxencias por Incend. en Galicia. URL http://www.fegamp.gal/sites/default/files/artigos/descargas/peifo gagal-definitivopublicadodog.pdf

Xunta de Galicia, 2014. Red Natura 2000 de Galicia [WWW Document].

https://www.xunta.gal/dog/Publicados/2014/20140331/Anuncio CA02-270314-0001 es.html

Xunta de Galicia, 2012. Ley 7/2012 de montes de Galicia [WWW Document]. Ley 7/2012, 28 junio, montes Galicia. URL https://www.boe.es/buscar/doc.php?id=BOE-A-201211414

Xunta de Galicia, 2007. Ley 3/2007, de 9 de abril, de prevención y defensa contra los incendios forestales. 